\title{
PENGARUH KEBUTUHAN PENGEMBANGAN DIRI (GROWTH NEED STRENGTH) DAN KARAKTERISTIK PEKERJAAN TERHADAP KEPUASAN KERJA GURU SMP NEGERI KECAMATAN KARAWANG BARAT KABUPATEN KARAWANG.
}

\author{
Anggie Andhini Pertiwi ${ }^{1}$
}

\begin{abstract}
: the objectives of this research was to investigate and to understand the effect of growth need strength and job characteristics on job satisfaction. It was a quantitative research which was conducted in six state junior high schools in West Karawang District located in Karawang Regency. The research used a survey method with path analysis applied in testing hyphotesis. The respondent sample are 151 teachers who are selected in a simple random way. The result of this research are: (1) There is a direct positive effect of growth need strength on job satisfaction. (2) There is a direct positive effect of job characteristics on job satisfaction. (3) There is a direct positive effect of growth need strength on job satisfaction.
\end{abstract}

Keywords: Growth need strength, job characteristics, and job satisfaction

\section{PENDAHULUAN}

Pembinaan dan pengembangan guru di sekolah tidak akan membawa hasil yang maksimal apabila faktor kepuasan kerja guru tidak diperhatikan. Pembinaan yang dilakukan kepala sekolah kepada guru, tidak akan dilaksanakan oleh guru, ketika guruguru menunjukkan ketidakpuasan akan kepemimpinan kepala sekolah. Kepala sekolah sebagai pemimpin harus menyadari bahwa kepuasan kerja guru adalah faktor pendorong guru-guru untuk maju dan bersedia dibina oleh kepala sekolahnya.

Seringkali pekerjaan guru disekolah terlalu rutin dan terspesialisasi sehingga jarang menawarkan kesempatan pertumbuhan psikologis khususnya mengembangkan potensi diri. Sekolah kadang-kadang kurang mendukung perkembangan potensi guru dan pimpinan sekolah jarang memberikan pembinaan yang semestinya. Pada akhirnya kepuasan kerja guru rendah dari aspek kepuasan terhadap tugas-tugas sebagai guru.

Terdapat tiga isu yang menunjukkan kepuasan guru di Kabupaten Karawang rendah, pertama masalah ketidakpuasan guru terhadap kepemimpinan kepala sekolah, adakalanya kepala sekolah kurang mendukung pengembangan potensi diri guru. Karena kuatir apabila guru-guru mengembangkan potensi diri akan melalaikan tugas mengajar. Kedua, ketidakpuasan guru terhadap pekerjaannya, guru-guru merasa kurang mendapat dukungan dari sekolah untuk tumbuh dan berkembang dalam meningkatkan profesionalisme hal ini ditunjukkan bahwa sedikit guru-guru yang terlibat MGMP dan kurang adanya dukungan sumber daya (dana dan fasilitas) yang memadai. Ketiga, tingginya beban kerja guru di sekolah-sekolah yang baru didirikan. Sekolah yang baru didirikan memiliki masalah dengan kesiapan sumber daya manusia,

\footnotetext{
${ }^{1}$ Guru SMA Negeri 1 Pangkalan
} 
sarana tempat dan fasilitas pendukung yang dikesampingkan. Sumber daya guru yang banyak merangkap, sedikitnya sumber daya manusia saling tumpang tindih pekerjaan.

Berdasarkan isu-isu tersebut maka kepuasan kerja guru adalah sesuatu hal yang perlu diperhatikan guna meningkatkan kinerja guru dan komitmen guru terhadap pekerjaannya, karena kepuasan kerja berkaitan erat dengan kinerja dan komitmen. Oleh karena itu perlu digali faktor-faktor yang menentukan kepuasan kerja guru diantaranya kebutuhan pengembangan diri rowth need strength) dan karakteristik pekerjaan.

\section{Kepuasan kerja}

Schermerhorn et.al, (2011:72) menjelaskan kepuasan kerja merupakan sebuah sikap, "job satisfaction, an attitude reflecting a person's positive and negative feelings toward a job, co-workers and the work environment". Kepuasan kerja sebuah sikap yang mencerminkan perasaan positif atau negatif dari seseorang terhadap pekerjaan, rekan kerja dan lingkungan kerja. Ivancevich et.al (2008:141) juga mengungkapkan kepuasan kerja sebagai sebuah sikap, "job satisfaction is an attitude that workers have about their jobs. Job satisfaction depends on the levels of intrinsic and extrinsic outcomes and how the job holder views those out come". Kepuasan kerja adalah sebuah sikap yang dimiliki pekerja mengenai pekerjaannya. Kepuasan kerja tergantung dari tingkat hasil keluaran secara intrinsik dan ekstrinsik dan bagaimana pekerja memandang hasil keluaran tersebut. Kinicki dan Kreitner (2008:192) mendefinisikan kepuasan kerja, "job satisfaction is an affective or emosional response toward various facets of one job". Kepuasan kerja adalah respon afektif atau emosional terhadap berbagai aspek dari suatu pekerjaan. Perasaan senang sebagai hasil persepsi seseorang tentang pekerjaannya juga dikemukakan oleh Wagner dan Hollenbeck (2010:106), "job satisfaction is a pleasurable feeling that results from the perception that one's job fulfills or allow for the fulfillment of one's important job values." Kepuasan kerja sebagai perasaan senang yang berasal dari persepsi bahwa pekerjaan seseorang dapat memenuhi atau menyebabkan terpenuhinya nilai kerja yang dianggap penting olehnya. Locke dalam Luthans (2011:141) memberikan definisi yang lengkap mengenai kepuasan kerja "locke gives a comprehensive definition of job satisfaction as involving cognitive, affective, and evaluative reactions or attitudes and states it is "a pleasurable or positive emotional state resulting from the appraisal of one's job or job experience." Locke memberikan definisi yang lengkap mengenai kepuasan kerja karena melibatkan kognitif, afektif dan evaluasi reaksi atau sikap dan menyatakannya sebagai "keadaan emosional yang menyenangkan atau positif hasil dari penilaian seseorang terhadap pekerjaannya atau pengalaman kerjanya.

Dari konsep di atas dapat dideskripsikan bahwa kepuasan kerja kepuasan kerja adalah sikap berupa perasaan emosi positif yang menyenangkan hasil penilaian seseorang terhadap pekerjaannya. Dengan indikator pengembangan diri, penghargaan atas hasil kerja, tanggung jawab, pencapaian hasil kerja, pengakuan atas hasil pekerjaan, dan lingkungan kerja. 


\section{Karakteristik Pekerjaan}

Istilah karakteristik pekerjaan menurut Hackman dan Oldham (2011:4) “job characteristics is a set of environmental variables that are widely thought to be important causes of employee effect and behavior". Artinya karakteristik pekerjaan adalah serangkaian variabel lingkungan yang secara luas dirasa penting yang menyebabkan dan mempengaruhi perilaku pekerja. Sedangkan menurut Schurman (2011:9) definisi karakteristik pekerjaan, "the definition of job characteristics is aspects specific to a job, such as knowledge and skills, mental and physical demands, and working conditions that can be recognized, defined, and assessed that are important causes of employee health." Karakteristik pekerjaan didefinisikan sebagai aspek khusus yang terdapat pada satu pekerjaan seperti pengetahuan dan keterampilan, tuntutan mental dan fisik yang diperlukan, dan kondisi pekerjaan yang dapat diketahui, didefinisikan dan dinilai yang merupakan penyebab kesehatan pegawai.

Kreitner dan Kinicki (2007:256) menyatakan karakteristik pekerjaan sebagai dimensi inti pekerjaan yaitu "core job dimensions are common characteristics found to a varying in all jobs " dimensi inti pekerjaan adalah karakteristik yang ditemukan dalam berbagai macam jenis pekerjaan.. Sedangkan Ivancevich, Konopaske, Matteson (2007:148) mengungkapkan, "perceived job content refers to characteristics of a job that define its general nature as perceived by the job holder". Dengan demikian ada istilah tersendiri mengenai karakteristik pekerjaan yaitu persepsi pekerja terhadap isi pekerjaan. Persepsi pekerja terhadap isi pekerjaan mengacu pada karakteristik sebuah pekerjaan yang mendefinisikan sifat umum pekerjaan seperti yang dirasa oleh pekerja.

Berdasarkan deskripsi di atas dapat disintesiskan karakteristik pekerjaan adalah aspek-aspek khusus dalam suatu pekerjaan yang menyebabkan tiga keadaan psikologis yaitu kebermaknaan, tanggung jawab, dan pengetahuan atas hasil pekerjaan sehingga menghasilkan motivasi intrinsik, kepuasan kerja, kinerja, rendahnya tingkat absensi dan pengunduran diri. Dengan indikator keanekaragaman keterampilan, identitas tugas, tuntutan pekerjaan, otonomi, umpan balik dan kesejahteraan.

\section{Kebutuhan Pengembangan Diri (Growth Need Strength)}

Hackman dan Oldham (2013:70) sebagai orang yang mengemukakan teori Job Characteristics Model mendefinisikan "growth need strength is a personality variable that explains to which degree individuals have needs for accomplishment, for learning, and for personal development". Kebutuhan pengembangan diri adalah variabel kepribadian yang menjelaskan sejauh mana individu mempunyai kebutuhan untuk pencapaian, pembelajaran dan perkembangan pribadi. George \& Jones (2012:194) memberikan definisi kebutuhan pengembangan diri, "growth-need strength is the extent to which an individual wants his or her work to contribute to personal growth, learning, and development". Kebutuhan pengembangan diri adalah sejauh mana seseorang berkeinginan supaya pekerjaannya berkontribusi/memberikan sumbangan untuk pengembangan pribadi, pembelajaran dan perkembangan. 
Definisi kebutuhan pengembangan diri menurut Hellriegel \& Slocum (2009:173) adalah "the extent to which an individual desires the opportunity for self-direction, learning, and personal accomplishment at work is called growth-need strength". Tingkatan keinginan seseorang untuk memperoleh kesempatan pengarahan diri, pembelajaran, dan pencapaian pribadi dalam pekerjaannya disebut kebutuhan pengembangan diri. Dari sisi pengembangan sumber daya manusia, Lepak dan Gowan (2010:191) menyatakan, "growth need strength is the extent to which individuals feel a need to learn and be challenged, a need to develop their skill beyond what they currently are, and a strong need for accomplishment". Kebutuhan pengembangan diri adalah tingkatan dimana seorang individu merasa butuh untuk belajar dan tertantang, butuh untuk mengembangkan keterampilan mereka diluar apa yang mereka kuasai saat ini dan kebutuhan yang kuat untuk pencapaian.

Shelley et.al., (2010:489) mengungkapkan definisi kebutuhan pengembangan diri yaitu, "so what exactly is "growth need strength"? it refers to an employee's desire to develop and improve herself in her current job". Jadi persisnya apakah kebutuhan pengembangan diri? Kebutuhan pengembangan diri mengacu pada keinginan seseorang untuk mengembangkan dan memperbaiki diri sendiri pada pekerjaan saat itu.

Sementara itu Colquitt (2009:116) mengutarakan bahwa "growth need strength which capture whether employees have strong needs for personal accomplishment or developing themselves beyond where they currently are". Kebutuhan pengembangan diri menandakan apakah para pegawai memiliki kebutuhan yang kuat untuk pencapaian pribadi atau mengembangkan diri mereka diluar kemampuan mereka sekarang. Pegawai yang memiliki kebutuhan pengembangan diri akan berusaha untuk memperkaya kemampuan mereka dibidang pekerjaan dan berusaha menambah pengetahuan agar selalu berkembang secara prestasi dan pencapaian. Berdasarkan deskripsi di atas maka kebutuhan pengembangan diri (GNS-Growth Need Strength) dapat disintesiskan keinginan seseorang untuk mengembangkan diri sehingga memberikan kontribusi terhadap pekerjaannya untuk suatu pencapaian pribadi. Dengan indikator kesempatan belajar, kesempatan memperbaiki diri, penghargaan diri, aktualisasi diri dan pengarahan diri.

\section{METODE}

Penelitian ini dilaksanakan dengan menggunakan pendekatan kuantitatif jenis asosiatif kausal metode survey dan teknik analisis jalur (path analysis). Penelitian ini dilakukan tiga bulan yaitu Bulan Maret dan diakhiri di Bulan Mei 2014. Penelitian ini dilakukan di SMP Negeri Kecamatan Karawang Barat Kabupaten Karawang yang memiliki 7 (Tujuh) SMP Negeri dengan jumlah total guru PNS sebanyak 243 orang guru. Sampel penelitian sebanyak 151 orang. Analisa data untuk pengujian hipotesis akan dilaksanakan dengan menggunakan analisis jalur, yaitu teknik yang diterapkan untuk menjelaskan pengaruh antara variabel-variabel penelitian. Sebelum dilaksanakan analisis jalur, uji signifikansi regresi dan uji linearitas sebagai prasyarat uji statistik dilakukan uji normalitas galat taksiran dari masing-masing variabel penelitian dengan 
Uji-Liliefors, statistik inferensial digunakan untuk menguji hipotesis tentang pengaruh antar variabel dengan menggunakan analisis jalur.

\section{HASIL DAN PEMBAHASAN}

\section{Pengaruh Kebutuhan Pengembangan Diri terhadap Kepuasan Kerja}

Hasil analisis korelasi sederhana antara kebutuhan pengembangan diri dengan kepuasan kerja dinyatakan dengan koefisien korelasi sebesar $r_{13}=0,438$ dan koefisien jalur sebesar $\rho_{31}=0,2118$. Dengan demikian pengaruh kebutuhan pengembangan diri terhadap kepuasan kerja cukup sedang atau positif, artinya dengan adanya kebutuhan pengembangan diri maka akan memperkuat kepuasan kerja guru SMP Negeri Kecamatan Karawang Barat di Kabupaten Karawang.

Berdasarkan teori karakteristik pekerjaan, kebutuhan pengembangan diri memiliki pengaruh untuk memperkuat atau memperlemah kepuasan kerja, seperti yang dinyatakan oleh Hackman and Oldham kebutuhan pengembangan diri berpengaruh terhadap keterkaitan antara karakteristik pekerjaan dan kepuasan kerja. Colquitt (2009:177) menyatakan kebutuhan pengembangan diri merupakan variabel moderator, "rather than directly affecting other variables in the diagram, moderators influence the strength of the relationships between variables". Sehingga agaknya daripada mempengaruhi secara langsung, kebutuhan pengembangan diri mempengaruhi keterkaitan antara variabel yaitu variabel karakteristik pekerjaan dan kepuasan kerja.

Kemudian Munchinsky (2006:408) menambahkan mengenai kebutuhan pengembangan diri yang menyebabkan kepuasan kerja, "individual who posses high growth need strength will exhibit high motivation on the job when the job is characterized by a high motivating potential score. It is also proposed that people in such jobs will experience high job satisfaction. High GNS employee were likely to have personal outcome and work outcome." Individu yang memiliki kebutuhan pengembangan diri tinggi akan menunjukkan tingginya motivasi pada pekerjaan ketika pekerjaan memiliki karakteristik melalui tingginya nilai potensi motivasi. Ini juga diusulkan bahwa orang-orang dalam pekerjaan tersebut akan mengalami kepuasan kerja yang tinggi. Pegawai dengan kebutuhan pengembangan diri tinggi akan menghasilkan keluaran pribadi yang menyenangkan dan hasil pekerjaan. Keluaran pribadi yang menyenangkan dapat berupa motivasi dan kepuasan sedangkan hasil pekerjaan berupa kinerja, rendahnya absensi dan pengunduran diri. Ivancevich et.al (2008:141) mengungkapkan kepuasan kerja sebagai sebuah sikap, "job satisfaction is an attitude that workers have about their jobs. Job satisfaction depends on the levels of intrinsic and extrinsic outcomes and how the job holder views those out come". Kepuasan kerja adalah sebuah sikap yang dimiliki pekerja mengenai pekerjaannya. Kepuasan kerja tergantung dari tingkat hasil keluaran secara intrinsik dan ekstrinsik dan bagaimana pekerja memandang hasil keluaran tersebut. Kinicki dan Kreitner (2008:192) mendefinisikan kepuasan kerja, "job satisfaction is an affective or emosional response toward various facets of one job". Kepuasan kerja adalah respon afektif 
atau emosional terhadap berbagai aspek dari suatu pekerjaan. Perasaan senang sebagai hasil persepsi seseorang tentang pekerjaannya juga dikemukakan oleh Wagner dan Hollenbeck (2010:106), "job satisfaction is a pleasurable feeling that results from the perception that one's job fulfills or allow for the fulfillment of one's important job values." Kepuasan kerja sebagai perasaan senang yang berasal dari persepsi bahwa pekerjaan seseorang dapat memenuhi atau menyebabkan terpenuhinya nilai kerja yang dianggap penting olehnya. Locke dalam Luthans (2011:141) memberikan definisi yang lengkap mengenai kepuasan kerja "locke gives a comprehensive definition of job satisfaction as involving cognitive, affective, and evaluative reactions or attitudes and states it is "a pleasurable or positive emotional state resulting from the appraisal of one's job or job experience." Locke memberikan definisi yang lengkap mengenai kepuasan kerja karena melibatkan kognitif, afektif dan evaluasi reaksi atau sikap dan menyatakannya sebagai "keadaan emosional yang menyenangkan atau positif hasil dari penilaian seseorang terhadap pekerjaannya atau pengalaman kerjanya.

Dengan demikian hasil penelitian menunjukan bahwa terdapat pengaruh positif kebutuham pengembangan diri terhadap kepuasan kerja.

\section{Pengaruh Karakteristik Pekerjaan terhadap Kepuasan Kerja}

Hasil analisis korelasi sederhana antara karakteristik pekerjaan dengan kepuasan kerja mendapatkan koefisien korelasi sebesar $r_{23}=0,4922$ dan koefisien jalur $\rho_{32}=0,590$. Dengan demikian pengaruh karakteristik pekerjaan terhadap kepuasan kerja cenderung cukup sedang atau positif, artinya semakin banyak karakteristik dalam pekerjaan tugas guru maka akan menyebabkan kepuasan kerja guru meningkat.

Berkaitan dengan teori karakteristik pekerjaan dapat mempengaruhi kepuasan kerja, sebagaimana diungkapkan Schermerhorn (2011:143) bahwa "on average job characteristics do effect performance but not nearly as much as they do satisfaction. Positive job characteristics affect performance more strongly for high-growth-need than for low-growth-need individuals. The relationship is about the same with the job satisfaction". Secara rata-rata kerakteristik pekerjaan mempengaruhi kinerja namun tidak sebesar pengaruh antara karakteristik pekerjaan terhadap kepuasan. Karakteristik pekerjaan berpengaruh positif terhadap kinerja lebih kuat pada individu yang memiliki kebutuhan pengembangan diri tinggi daripada individu dengan kebutuhan pengembangan diri rendah. Keterkaitan ini sama halnya dengan kepuasan kerja.

Selanjutnya Perie, Baker dan Whitener (2003:88) mengungkapkan bahwa kepuasan guru dipengaruhi karakteristik pekerjaan, "the authors found that the most important influences on job satisfaction were work characteristics. Teachers who felt that they had an influence over school policy and felt they were in control of their classroom were much more likely to be satisfied with their jobs than teachers who felt they did not have influence or control". Pengarang menemukan bahwa yang paling penting mempengaruhi kepuasan kerja adalah karakteristik pekerjaan. Guru-guru yang merasa mereka memberikan pengaruh pada kebijakan sekolah dan merasa mereka mempunyai kendali terhadap 
kelasnya lebih merasa puas dengan pekerjaannya daripada guru-guru yang merasa mereka tidak mempunyai pengaruh atau kendali

Kelly (2005:343) juga mendukung bahwa karakteristik pekerjaan mempengaruhi kepuasan kerja. Berdasarkan penelitiannya tentang karakteristik pekerjaan diketahui bahwa, "changes in work methods, pay rates, job security, goals and individual rewards can occur as a result of job redesign, as well as (or instead of) changes in job characteristics. Changes in job characteristics affect satisfaction and motivation, but the other changes have a more direct impact on job performance". Perubahan dalam metode bekerja, rata-rata upah, keamanan pekerjaan, tujuan dan penghargaan individu dapat terjadi sebagai hasil dari kembali merancang pekerjaan, sama halnya dengan perubahan dalam karakteristik pekerjaan. perubahan dalam karakteristik pekerjaan mempengaruhi kepuasan dan motivasi, tetapi perubahan lainnya mempunyai pengaruh lebih langsung terhadap kinerja. Hackman dan Oldham (2011:4) menjelaskan "job characteristics is a set of environmental variables that are widely thought to be important causes of employee effect and behavior". Karakteristik pekerjaan adalah serangkaian variabel lingkungan yang secara luas dirasa penting yang menyebabkan dan mempengaruhi perilaku pekerja. Sedangkan menurut Schurman (2011:9) definisi karakteristik pekerjaan, "the definition of job characteristics is aspects specific to a job, such as knowledge and skills, mental and physical demands, and working conditions that can be recognized, defined, and assessed that are important causes of employee health." Karakteristik pekerjaan didefinisikan sebagai aspek khusus yang terdapat pada satu pekerjaan seperti pengetahuan dan keterampilan, tuntutan mental dan fisik yang diperlukan, dan kondisi pekerjaan yang dapat diketahui, didefinisikan dan dinilai yang merupakan penyebab kesehatan pegawai.

Kreitner dan Kinicki (2007:256) menyatakan karakteristik pekerjaan sebagai dimensi inti pekerjaan yaitu "core job dimensions are common characteristics found to a varying in all jobs " dimensi inti pekerjaan adalah karakteristik yang ditemukan dalam berbagai macam jenis pekerjaan.. Sedangkan Ivancevich, Konopaske, Matteson (2007:148) mengungkapkan, "perceived job content refers to characteristics of a job that define its general nature as perceived by the job holder". Dengan demikian ada istilah tersendiri mengenai karakteristik pekerjaan yaitu persepsi pekerja terhadap isi pekerjaan. Hackman dan Oldham (2011:4) "job characteristics is a set of environmental variables that are widely thought to be important causes of employee effect and behavior". Karakteristik pekerjaan adalah serangkaian variabel lingkungan yang secara luas dirasa penting yang menyebabkan dan mempengaruhi perilaku pekerja. Sedangkan menurut Schurman (2011:9) menjelaskan, "the definition of job characteristics is aspects specific to a job, such as knowledge and skills, mental and physical demands, and working conditions that can be recognized, defined, and assessed that are important causes of employee health." Karakteristik pekerjaan didefinisikan sebagai aspek khusus yang terdapat pada satu pekerjaan seperti pengetahuan dan keterampilan, tuntutan mental dan fisik yang diperlukan, dan kondisi pekerjaan yang dapat diketahui, didefinisikan dan dinilai yang merupakan penyebab kesehatan pegawai. 
Kreitner dan Kinicki (2007:256) menyatakan karakteristik pekerjaan sebagai dimensi inti pekerjaan yaitu "core job dimensions are common characteristics found to a varying in all jobs " dimensi inti pekerjaan adalah karakteristik yang ditemukan dalam berbagai macam jenis pekerjaan.. Sedangkan Ivancevich, Konopaske, Matteson (2007:148) mengungkapkan, "perceived job content refers to characteristics of a job that define its general nature as perceived by the job holder". Dengan demikian ada istilah tersendiri mengenai karakteristik pekerjaan yaitu persepsi pekerja terhadap isi pekerjaan. Dengan demikian hasil penelitian menunjukkan bahwa terdapat pengaruh positif karakteristik pekerjaan terhadap kepuasan kerja.

\section{Pengaruh Kebutuhan Pengembangan Diri terhadap Karakteristik Pekerjaan}

Hasil analisis korelasi sederhana antara kebutuhan pengembangan diri dengan karakteristik pekerjaan memperoleh koefisien korelasi sebesar $r_{12}=0,460$ dan koefisien jalur $\rho_{21}=0,460$. Dengan demikian pengaruh kebutuhan pengembangan diri terhadap karakteristik pekerjaan cukup sedang atau positif, artinya kebutuhan pengembangan diri akan membuat karakteristik pekerjaan yang ia terima dalam tugasnya semakin memadai.

Berdasarkan teori model karakteristik pekerjaan, variabel yang mempengaruhi karakteristik pekerjaan adalah kekuatan pegawai untuk kebutuhan pengembangan diri. Sebagaimana diungkapkan oleh Muchinsky (2006:409) mengungkapkan," In general, the result showed that jobs high on the core job dimensions were assosiated with the levels of motivation. Individual with high GNS responded most favorably to these type of jobs. Likewise, over time people with high GNS might tend to gravitate toward more complex jobs, while people with low GNS might tend to gravitate toward more simple jobs." Secara umum hasil menunjukkan bahwa pekerjaan yang tinggi dimensi inti pekerjaan diasosiasikan dengan tingginya level motivasi. Individu dengan tingginya kebutuhan pengembangan diri (GNS) akan merespon dengan senang jenis pekerjaan-pekerjaan ini. Demikian juga dari waktu ke waktu orang dengan GNS yang tinggi akan bergerak menuju pekerjaan yang lebih rumit. Sementara orang dengan GNS yang rendah mungkin cenderung bergerak menuju pekerjaan yang lebih sederhana.

Selanjutnya Daft (2008:543) menyatakan bahwa, "people with a high need to grow and expand their abilities respon favorably to the application of the model and to improvements in core job dimensions". Orang dengan kebutuhan untuk pengembangan diri yang tinggi dan memperluas kemampuannya akan menanggapi dengan senang akan penerapan model ini dan perbaikan dalam hal dimensi inti pekerjaan. Hackman dan Oldham (2013:70) sebagai orang yang mengemukakan teori Job Characteristics Model mendefinisikan "growth need strength is a personality variable that explains to which degree individuals have needs for accomplishment, for learning, and for personal development". Kebutuhan pengembangan diri adalah variabel kepribadian yang menjelaskan sejauh mana individu mempunyai kebutuhan untuk pencapaian, pembelajaran dan perkembangan pribadi. George \& Jones (2012:194) memberikan definisi kebutuhan 
pengembangan diri, "growth-need strength is the extent to which an individual wants his or her work to contribute to personal growth, learning, and development". Kebutuhan pengembangan diri adalah sejauh mana seseorang berkeinginan supaya pekerjaannya berkontribusi/memberikan sumbangan untuk pengembangan pribadi, pembelajaran dan perkembangan.

Selanjutnya definisi kebutuhan pengembangan diri menurut Hellriegel \& Slocum (2009:173) adalah "the extent to which an individual desires the opportunity for selfdirection, learning, and personal accomplishment at work is called growth-need strength". Tingkatan keinginan seseorang untuk memperoleh kesempatan pengarahan diri, pembelajaran, dan pencapaian pribadi dalam pekerjaannya disebut kebutuhan pengembangan diri. Dari sisi pengembangan sumber daya manusia, Lepak dan Gowan (2010:191) menyatakan, "growth need strength is the extent to which individuals feel a need to learn and be challenged, a need to develop their skill beyond what they currently are, and a strong need for accomplishment". Kebutuhan pengembangan diri adalah tingkatan dimana seorang individu merasa butuh untuk belajar dan tertantang, butuh untuk mengembangkan keterampilan mereka diluar apa yang mereka kuasai saat ini dan kebutuhan yang kuat untuk pencapaian.

Shelley et.al., (2010:489) mengungkapkan definisi kebutuhan pengembangan diri yaitu, "so what exactly is "growth need strength"? it refers to an employee's desire to develop and improve herself in her current job". Jadi persisnya apakah kebutuhan pengembangan diri? Kebutuhan pengembangan diri mengacu pada keinginan seseorang untuk mengembangkan dan memperbaiki diri sendiri pada pekerjaan saat itu. Sementara itu Colquitt (2009:116) mengutarakan bahwa "growth need strength which capture whether employees have strong needs for personal accomplishment or developing themselves beyond where they currently are". Kebutuhan pengembangan diri menandakan apakah para pegawai memiliki kebutuhan yang kuat untuk pencapaian pribadi atau mengembangkan diri mereka di luar kemampuan mereka sekarang. Dengan demikian hasil penelitian menunjukkan bahwa terdapat pengaruh positif kebutuhan pengembangan diri terhadap karakteristik pekerjaan.

\section{PENUTUP}

Kesimpulan: Berdasarkan hasil analisa dan kajian dari penelitian ini dapat disimpulkan bahwa: (1). Kebutuhan pengembangan diri berpengaruh langsung positif terhadap kepuasan kerja guru. Ini bermakna bahwa kebutuhan pengembangan diri dalam guru dapat menyebabkan timbulnya kepuasan kerja. (2). Karakteristik pekerjaan berpengaruh langsung positif terhadap kepuasan kerja. Ini berarti karakteristik pekerjaan yang ada dalam tugas guru dapat menyebabkan meningkatnya kepuasan kerja. (3). Kebutuhan pengembangan diri berpengaruh langsung positif terhadap karakteristik pekerjaan. hal ini mengandung makna bahwa kebutuhan pengembangan diri akan menyebabkan seseorang merasa pekerjaannya memiliki karakteristik yang memadai sehingga ia menyenangi pekerjaannya. 
Saran: (1).Untuk Kepala Sekolah agar mampu memberikan kesempatan guru untuk mengembangkan diri dan sumber daya manusia dengan mempermudah izin guru untuk melanjutkan pendidikan ke jenjang yang lebih tinggi dan mengikuti berbagai pelatihan pelatihan-pelatihan maupun seminar untuk membuka wawasan guru (2). Untuk Kepala Dinas Pendidikan Kabupaten Karawang agar memfasilitasi dan memberikan kesempatan bagi guru-guru mengembangkan potensi sumber daya manusia melalui perbaikan karakteristik pekerjaan dari tugas guru sehingga guru dapat mengembangkan seluruh kemampuan dan keterampilan. (3) Untuk menumbuhkan dan mengembangkan kepuasan kerja guru dari aspek pekerjaan maka pemerintah, pemerintah daerah dan pemimpin-pemimpin yang berkompeten dalam pengembangan dan peningkatan kearah perubahan mutu pendidikan yang handal, agar dapat mengikut sertakan guru-guru dalam kegiatan pelatihan-pelatihan maupun seminar untuk membuka wawasan guru dan memberi kesempatan pada guru untuk melanjutkan pendidikan ke jenjang yang lebih tinggi dalam rangka peningkatan kualitas guru.

\section{DAFTAR PUSTAKA}

Arnold, John. Work Psychology Understanding Human Behavior in the Work Place. London: Prentice Hall, 2005.

Daft, Richard L. Management. Mason: Thomson-South Western , 2008.

Gowan, David Lepak \& Mary. Human Resources Management. New Jersey: Pearson Prentice-Hall, 2010.

Hollenbeck, John A. Wagner \& John R. Organizational Behavior Securing Competitive Advantage. New York: Routledge, 2010.

John (jack) M. Ivancevich, Robert Konopaske,Michael T. Matteson. Organizational Behavior and Management Eighth Edition. New York: McGraw-Hill Companies, 2008.

John R Schermerhorn, Jr. Organizational Behavior 11th edition. USA: John Wiley \& Sons, 2011.

John W Slocum, Jr \& Don Hellriegel. Principles of Organizational Behavior, 12th ed. Canada: South Western-Cencage Learning, 2009.

Kinicki, Robert Kreitner-Angelo. Organizational Behavior-Seventh Edition . New York: McGraw-Hill Company, 2007.

Luthans, Fred. Organizational Behavior, 12th editions . New York: Mc Graw Hill, 2011. 
R.Jones, Jennifer M.George \& Gareth. Understanding and Managing Organizational Behavior- Sixth Edition. New Jersey: Pearson Education, 2012.

Schuurman, Jasper. Job Characteristics, Health \& Satisfaction. Rotterdam: Netspar, 2011.

Shelley CE, Gilson LL \& Blum TC, "Interactive effects of growth need strength, work context, and job complexity on self-reported creative performance". Academy of Management Journal, Vol.52, No.3. pp.489-505,

http://www.ioatwork.com/tag/growth-need-strength/ (diakses 22 Desember 2013) 